\title{
MICROMECHANICAL MODELING ON CYCLIC PLASTIC BEHAVIOR OF UNIDIRECTIONAL FIBER REINFORCED ALUMINUM MATRIX COMPOSITES
}

\author{
Dario Giugliano and Haofeng Chen* \\ Department of Mechanical and Aerospace Engineering, University of Strathclyde \\ Glasgow, G1 1XJ, United Kingdom \\ *Email: Haofeng.chen@strath.ac.uk
}

\begin{abstract}
This work investigates the cyclic plastic behavior of continuous fiber-reinforced aluminum matrix composites (CFAMCs) with different volume fractions of fiber up to a maximum value of $63.61 \%$ using micromechanical approach of modeling. Shakedown, ratcheting limit and load-bearing capacity have been studied. The FEM models, based on two dimensional micromechanical representative volume element (RVE) with a square packing geometry, were subjected to constant macro stress under off-axis loading condition and thermal cycling conditions. A number of direct numerical methods, under the Linear Matching Method (LMM) framework, are adopted for the determination of limit load, reverse plasticity limit and ratchet limit of AMCs. The typical micromechanical model adopted in all analysis consists of continuous fibers with circular cross section, embedded in an aluminum matrix. Two most common reinforcing materials alumina and silicon carbide are investigated. Various factors that affect shakedown and ratcheting behaviors of composites are analyzed and discussed, including effects of fiber volume fraction and temperature on the AMC's low cycle fatigue life.
\end{abstract}

Keywords: Shakedown, Ratchetting, Cyclic Plasticity, Metal Matrix Composite (MMC), Linear Matching Method (LMM)

\section{INTRODUCTION}

Metal Matrix Composites (MMCs) are high performance engineering materials highly employed in high-tech structural applications including automotive, defense and aerospace, due to their highstrength, lightweight and high-temperature capacity (Suryanarayanan et al., 2013). In order to take advantage of the potential that MMCs can give to enhanced performance components, there are significant needs for improvements and refinement in the design and modeling of composite materials. The inelastic behaviors of MMCs reinforced with either ceramic fibers or particles have been discussed by many researchers (Davis et al., 1998; Dvorak et al., 1988; Farrissey et al., 1999; Ge and Gu, 2001; Han et al., 2001; Jansson and Leckif, 1992; Kang et al., 2006; Ponter, 2001; Ponter and Leckie, 1998a, b; Tarn et al., 1975; Teply and Dvorak, 1988; Zhang et al., 2001; Zhang and Anderson, 1994; Zhang et al., 1990, 1991).

Metal matrix composites exhibit significant inelastic behavior under high off-axis loading conditions due to the nonlinearity of the matrix beyond the yield strength. Therefore the combined effect of both thermal cycling conditions and off-axis constant macro stress on such materials is potentially difficult to understand. The significantly differing coefficients of thermal expansion (CTE) between reinforced and matrix materials give rise to micro thermal stresses when the uniform temperature of the material is changed, having the possibility to cause low cycle fatigue (LCF) at the material interface or thermal ratcheting with relatively low mechanical load. 
The effects of particle volume ratios and particle arrangement on the MMCs' mechanical response as well as the strengthening effects of particles have been investigated by a number of researchers (Davis et al., 1998; Farrissey et al., 1999; Ge and Gu, 2001; Han et al., 2001; Suryanarayanan et al., 2013; Zhang et al., 2001; Zhang et al., 1990). For MMCs, due to the CTEs mismatch between the constituents, thermally induced stresses occur on the micro scale. The effects on this strengthening of variable uniform temperature for fiber reinforced composites have also been studied (Dvorak et al., 1988; Jansson and Leckif, 1992; Kang et al., 2006; Ponter, 2001; Ponter and Leckie, 1998a, b; Tarn et al., 1975; Teply and Dvorak, 1988; Zhang and Anderson, 1994; Zhang et al., 1991) using either the experimental methods or numerical simulations. Among these numerical methods, the Linear Matching Methods (LMMs) (Chen and Ponter, 2005) was adopted to investigate the cyclic plastic behaviors of a particulate reinforced MMC subjected to thermal cyclic loading conditions and constant stress. For the first time, a wide range design limits including the limit load, shakedown limit, and ratchet limit have been obtained comprehensively as non-dimensional equations for the design purpose. However, unlike the shakedown analysis method (Chen, 2010), the LMM ratchet analysis method (Chen and Ponter, 2001) adopted in (Chen and Ponter, 2005) was still in its infancy and not able to properly evaluate the ratchet limit when the variation of temperature is sufficiently large, due to the excessive numerical treatment in order to ensure a stable convergence. For large thermal amplitudes and small applied macro stress, there are many experimental evidences (Jansson and Leckif, 1992; Ponter and Leckie, 1998a, b) that cyclic strain growth (ratcheting) occurs. However, the LMM in (Chen and Ponter, 2005) predicts reverse plasticity, and these solutions need to be reinvestigated.

Since then, as a direct method aimed at answering specific design related problems using standard finite element codes, the LMM has been much developed to characterize the steady state cyclic behavior of structures including the accurate estimation of the ratchet limit and various plastic mechanisms (Chen and Ponter, 2010). Significant strides on the associated structural analysis tool based on the Linear Matching Method framework for the assessment of design limits for monotonic and cyclic plasticity behavior of structures at the steady state were also accomplished using Abaqus CAE plugins with graphical user interfaces (Chen et al., 2014; Ure et al., 2014).

Metallic structures including MMCs, under cyclic loading conditions, can exhibit four modes of behavior depending upon the applied load level: 1) for sufficiently low value of the applied load, the elastic stresses lie within yield leading to elastic behavior alone; 2) the elastic stress history go beyond yield, and the plastic strains occur during the initial load cycles. The build-up of the residual stress could be such that no further plastic strain occurs after a limited number of load cycles. The occurrence of this behavior in a structure is said elastic shakedown; 3) the applied load level exceeds the elastic shakedown limit but in the matrix no cyclic strain growth arises i.e. locally, a closed loop characterized by the plastic strain history occurs and the structure exhibits reverse plasticity; 4) the structure undergoes an incremental plastic collapse if the cyclic loads applied go beyond the ratchet limit. This cyclic growth of plastic strain is known as ratcheting.

The general approach for investigating these patterns of behavior of a metallic structure e.g. metal matrix may be obtained through incremental FEA i.e. a large number of step by step finite element calculations (Hibbitt, 1997). However, this can be difficult, very time-consuming and essentially subjective. The latest development of the LMM aimed at identifies the limit region boundaries accurately and efficiently. Although the improved computational method has been applied for addressing design and life assessment issues for many high temperature power plant components (Chen et al., 2014), it is a first attempt to apply the new LMM to comprehensively characterize the cyclic inelastic behaviors of a continuous fiber reinforced MMC.

The aim of this paper is to characterize the cyclic plastic behavior of the AMCs in terms of the variation of the reinforced fiber material and its volume ratio. Another objective of the paper is to use 
the new LMM shakedown and ratchet analysis methods and tool to investigate the combined effects of constant macro stress and thermal cycling conditions on the low cycle fatigue (LCF) life along the transversal direction for the AMCs considering two common reinforcing materials alumina $\left(\mathrm{Al}_{2} \mathrm{O}_{3}\right)$ and silicon carbide $\left(\mathrm{S}_{\mathrm{i}} \mathrm{C}\right)$, and to demonstrate the ratcheting failure mechanism identified by experiments for large thermal amplitudes and small applied macro stress. In the following sections, numerical procedure of the LMM is provided along with the problem description and the detailed finite element model of the fiber reinforced AMC. This is followed by the presentation of detailed limit loads, shakedown limits and ratchet limits of the fiber reinforced AMCs in section 4. The effects of different fiber materials, fiber volume fractions and temperatures on the AMC's plastic behaviors are analyzed and discussed. A non-dimensional equation is provided for LCF assessment of AMCs.

\section{THE LINEAR MATCHING METHOD}

The LMM employed in the present paper for characterizing efficiently the low cycle thermomechanical fatigue has been widely described in (Chen, 2010; Chen and Ponter, 2010). Hence a brief summary of this numerical procedure is provided in this section. The theoretical basis of the LMM is supported by the idea that the cyclic stress and nonlinear strain are represented by a series of iterative linear elastic solutions where the moduli varies spatially and with time.

Let us take into account an isotropic, elastic-perfectly plastic medium occupying the volume $\mathrm{V}$ and enclosed by the surface S. We shall henceforth assume that the material fulfill the von Mises yield criterion and undergoes to a cyclic history of temperature $\lambda \theta(x, t)$ throughout its volume $\mathrm{V}$ whilst only a portion $\left(\mathrm{S}_{\mathrm{T}}\right)$ of the body surface $\mathrm{S}$, undergoes a history of cyclic mechanical load $\lambda P(x, t)$, $\lambda$ being a scalar load parameter and $\theta(x, t)$ and $P(x, t)$ having the same cycle time $\Delta t$. The complementary part of $\mathrm{S}, \mathrm{S}_{\mathrm{u}}=\mathrm{S}-\mathrm{S}_{\mathrm{T}}$, is instead fixed. As a consequence of the hypotheses above, at large enough cycles the stresses and strain rates are approximated by cyclic states, i.e.,

$$
\sigma_{i j}(t)=\sigma_{i j}(t+\Delta t), \dot{\varepsilon}_{i j}(t)=\dot{\varepsilon}_{i j}(t+\Delta t)
$$

The resulting asymptotic stress history may be decomposed as the sum of three terms through

$$
\sigma_{i j}(x, t)=\lambda \hat{\sigma}_{i j}(x, t)+\bar{\rho}_{i j}(x)+\rho_{i j}^{r}(x, t)
$$

where $\lambda \hat{\sigma}_{i j}$ is the linear cyclic elastic stress solution, $\bar{\rho}_{i j}$ represents a spatial dependent residual stress field in equilibrium with no traction acting on $S_{T}$ corresponding to the residual stress field at the beginning and end of the cycle, while $\rho_{i j}^{r}$ represents the residual stress occurring within the cycle and fulfills

$$
\rho_{i j}^{r}(x, 0)=\rho_{i j}^{r}(x, \Delta t)=\bar{\rho}_{i j}^{r}
$$

It must be noted that the cyclic stress and strain history described above are applied to any inelastic materials.

\subsection{THE EVALUATION OF THE SHAKEDOWN LIMIT}

The general methodology involved in the LMM has the aim to solve sequentially a set of linear problems that allows the calculation of the upper bound shakedown limit at each numerical iteration starting from a kinematically admissible strain history. Thus the result has been computed as the monotonic reduction of the upper bound shakedown limit tends to the least upper bound (Chen, 2010). The lower bound of shakedown limit has also been calculated using a direct algorithm presented in (Chen, 2010). Such a method employs the most accurate residual stress field computed during the 
upper bound procedure with displacement-based finite elements analyses.

For shakedown conditions the varying residual stress $\rho_{i j}^{r}$ must equal zero, leading to a cyclic stress history at shakedown

$$
\sigma_{i j}(x, t)=\lambda \hat{\sigma}_{i j}(x, t)+\bar{\rho}_{i j}(x)
$$

The upper bound shakedown limit, $\lambda_{\mathrm{UB}}$ is given by

$$
\lambda_{U B}=\frac{\int_{V} \int_{0}^{\Delta t} \sigma_{y} \overline{\dot{\varepsilon}}\left(\dot{\varepsilon}_{i j}\right) d t d V}{\int_{V} \int_{0}^{\Delta t}\left(\hat{\sigma}_{i j} \dot{\varepsilon}_{i j}\right) d t d V}
$$

where $\sigma_{\mathrm{y}}$ is the temperature-dependent yield stress of material, $\dot{\varepsilon}_{\mathrm{ij}}$ is a kinematically admissible strain rate and $\overline{\dot{\varepsilon}}=\sqrt{\frac{2}{3} \dot{\varepsilon}_{\mathrm{ij}} \dot{\varepsilon}_{\mathrm{ij}}}$ is the effective strain rate. By definition of shakedown in a structure no plastic strain accumulation will occur when the combination of the applied elastic stresses and a constant residual stress field satisfies the von Mises yield criterion at any location. Therefore the lower bound of shakedown limit can be computed by checking equation (6) at each integration points for all load instances

$$
f\left(\lambda_{L B} \hat{\sigma}_{i j}\left(x_{i}, t\right)+\bar{\rho}_{i j}\left(x_{i}\right)\right) \leq 0
$$

where $\lambda_{\mathrm{LB}}$ is the lower bound shakedown multiplier.

This procedure was implemented within ABAQUS (Hibbitt, 1997) adopting UMAT user subroutine. For a given strain increment, the algorithm computes iteratively the shear modulus (equation (12) in (Chen, 2010)), the Jacobian matrix, the residual stress and the updated stress. Using the shakedown procedure as a special case it is also possible to perform the limit analysis. A full description of the numerical procedure for LMM shakedown analysis is reported in (Chen, 2010).

\subsection{EVALUATION OF THE RATCHET LIMIT}

When a predefined cyclic load history is applied to a structure, a two steps procedure can be adopted to evaluate the ratchet limit related to an additional constant load. By considering the equation (2), the changing residual stress $\rho_{i j}^{r}(x, t)$ and the constant residual stress $\bar{\rho}_{i j}(x)$ may be decoupled and evaluated separately. The first step involves the evaluation of $\rho_{i j}^{r}(x, t)$ produced by the predefined cyclic load history along with the corresponding plastic strain ranges that is fundamental to assess the low fatigue crack initiation. In the second step the traditional shakedown procedure is adopted to assess the ratchet limit. The constant residual stress $\bar{\rho}_{i j}(x)$ is calculated and the elastic stress history is enhanced by the changing residual stress $\rho_{i j}^{r}(x, t)$ calculated in the previous step.

The first step that evaluates the changing residual stress field $\rho_{i j}^{r}(x, t)$ (Chen and Ponter, 2010) is known as Direct Steady Cycle Analysis (DSCA) in the LMM framework. This DSCA procedure is established on a series of iterative cycles which are defined as $m=1,2 \ldots \mathrm{M}$. Within each iterative subcycle, there will be a number of increments, which are defined as $\mathrm{n}=1,2 \ldots \mathrm{N}$ for $\mathrm{N}$ load instances. A linear matching process has been created in (Chen and Ponter, 2010) to iteratively calculate each individual varying residual stress $\Delta \rho_{i j}^{r}\left(x, t_{n}\right)_{m}$ associated with each elastic solution $\hat{\sigma}_{i j}^{\Delta}\left(x, t_{n}\right)$, from n 
$=1,2 \ldots \mathrm{N}$, until convergence is reached at cycle $\mathrm{M}$. The constant residual stress term in equation (3) can then be calculated as;

$$
\bar{\rho}_{i j}^{r}(x)=\sum_{m=1}^{M} \sum_{n=1}^{N} \Delta \rho_{i j}^{r}\left(x, t_{n}\right)_{m}
$$

Thus, the changing residual stress $\rho_{i j}^{r}\left(x, t_{n}\right)$ at the steady state cycle can be represented as;

$$
\rho_{i j}^{r}\left(x, t_{n}\right)=\bar{\rho}_{i j}^{r}(x)+\sum_{k=1}^{n} \Delta \rho_{i j}^{r}\left(x, t_{k}\right)_{M}
$$

The associated converged plastic strain increment occurring at time $t_{n}$ is assessed by

$$
\Delta \varepsilon_{i j}^{p}\left(x, t_{n}\right)=\frac{1}{2 \bar{\mu}_{n}\left(x, t_{n}\right)}\left[\hat{\sigma}_{i j}^{\Delta^{\prime}}\left(x, t_{n}\right)+\rho_{i j}^{r^{\prime}}\left(x, t_{n}\right)\right]
$$

where $\bar{\mu}_{n}$ is the iterative shear modulus determined by the linear matching equation (19) in (Chen and Ponter, 2010), the prime refers to the deviator component of stress and strain, and $\hat{\sigma}_{i j}^{\Delta}$ is the predefined cyclic linear elastic stress history.

Also for the mentioned LMM iterative procedure appropriate ABAQUS user subroutine UMAT has been developed and further described in (Chen and Ponter, 2010). On the basis of the obtained results in terms of accumulated residual stress history $\rho_{i j}^{r}\left(x, t_{n}\right)$ at the time point $t_{n}$ corresponding to the cyclic component of the load history, the calculation of the ratchet limit can be implemented within the current method of the shakedown analysis (Chen, 2010; Chen and Ponter, 2010), where the predefined cyclic linear elastic stress history is augmented by the varying residual stress field $\rho_{i j}^{r}\left(x, t_{n}\right)$.

Defining the von Mises yield condition with the associated flow rule, an upper bound on the ratchet limit multiplier associated with the additional constant mechanical load $\hat{\sigma}_{i j}^{\bar{F}}(x)$ is derived by

$$
\lambda=\frac{\int_{V} \sum_{n=1}^{N}\left(\sigma_{y} \bar{\varepsilon}\left(\Delta \varepsilon_{i j}^{n}\left(x, t_{n}\right)\right)\right) d V-\int_{V} \sum_{n=1}^{N}\left(\left(\hat{\sigma}_{i j}^{\Delta}\left(x, t_{n}\right)+\rho_{i j}^{r}\left(x, t_{n}\right)\right) \Delta \varepsilon_{i j}^{n}\left(x, t_{n}\right)\right) d V}{\int_{V} \hat{\sigma}_{i j}^{\bar{F}}(x)\left(\sum_{n=1}^{N} \Delta \varepsilon_{i j}^{n}\left(x, t_{n}\right)\right) d V}
$$

where $\bar{\varepsilon}\left(\Delta \varepsilon_{i j}^{n}\right)=\sqrt{\frac{2}{3} \Delta \varepsilon_{i j}^{n} \Delta \varepsilon_{i j}^{n}}$ and $\Delta \varepsilon_{i j}^{n}$ is the kinematically admissible plastic strain rate history. This ratchet limit multiplier is related to the capacity of the body subjected to a predefined cyclic load history $\hat{\sigma}_{i j}^{\Delta}\left(x, t_{n}\right)$ to endure an additional constant load $\hat{\sigma}_{i j}^{\bar{F}}(x)$ without ratcheting occurs. Once a class of displacement fields is fixed, equation (10) yields a sequence of monotonically reducing upper bounds, which iteratively converges to the least upper bound ratchet limit.

\section{PROBLEM DESCRIPTION AND THE FINITE ELEMENT MODEL}

An idealized, fiber-reinforced composite that consists of a periodic array arranged with a square packing geometry is taken into account to investigate the off-axis inelastic behavior of the AMCs subjected to combined action of cyclic thermal and constant mechanical loading. 

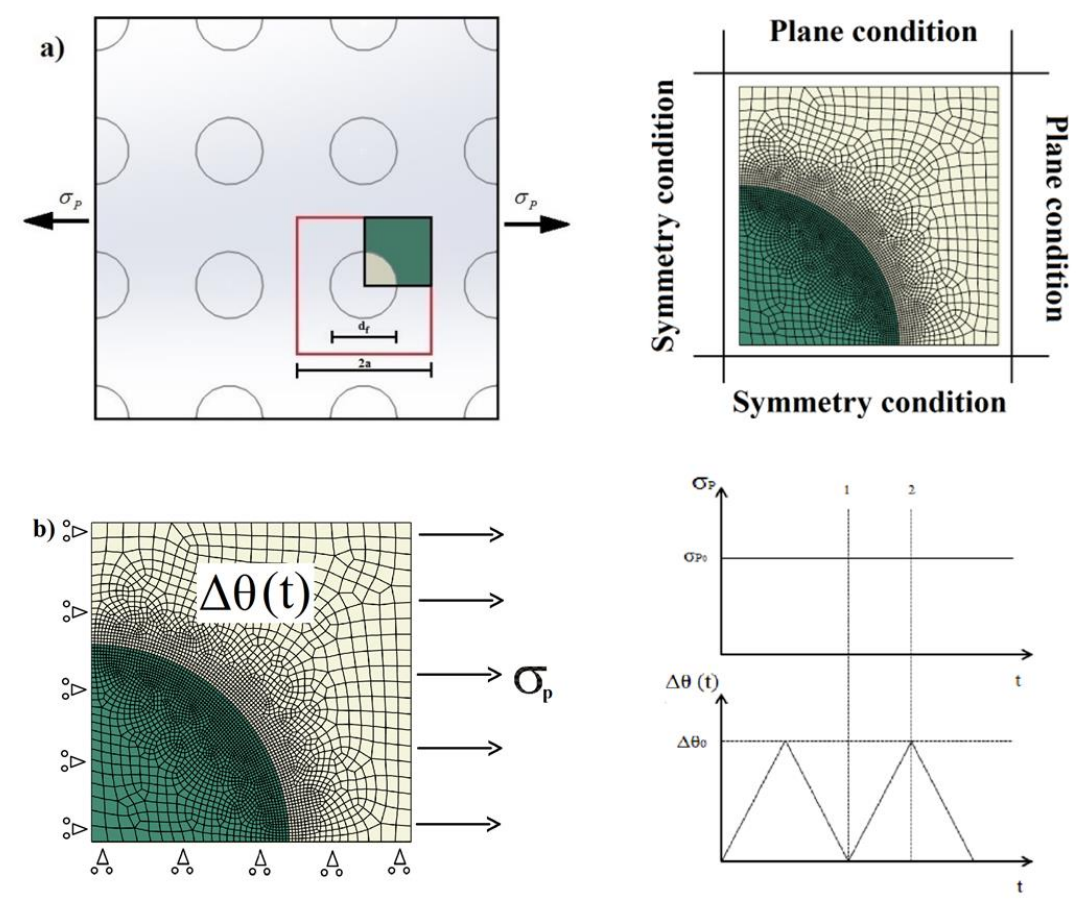

Fig. 1. a) The unit cell used in the FEA; b) Applied cyclic loading.

Table 1 Material properties.

\begin{tabular}{lccc}
\hline Material property & $\mathbf{A l}$ & $\mathbf{A l}_{\mathbf{2}} \mathbf{O}_{\mathbf{3}}$ & $\mathbf{S}_{\mathbf{i}} \mathbf{C}$ \\
\hline Young's modulus E (GPa) & 70 & 370 & 450 \\
Thermal expansion & 22 & 8 & 4 \\
coefficient $\alpha\left(\mathrm{MK}^{-1}\right)$ & 80 & 5000 & 10000 \\
Yield stress $\sigma_{\mathrm{y}}(\mathrm{MPa})$ & 0.34 & 0.26 & 0.15 \\
Poisson's ratio $v$ & & & \\
\hline
\end{tabular}

The typical Abaqus FEA model used throughout this study is given in Fig. 1, with the detailed mesh scheme and boundary conditions. Quadrilateral plane strain elements were employed in all LMM shakedown and ratchet analysis. Symmetry reduces the necessary calculations to one quarter of the array. Two ceramic reinforcements $\mathrm{Al}_{2} \mathrm{O}_{3}$ and $\mathrm{S}_{\mathrm{i}} \mathrm{C}$ perfectly bound to an aluminum matrix have been considered. A linear elastic constitutive model has been employed for the fibers whilst a perfectly plastic model has been adopted for the matrix. The material properties used are presented in Table 1 .

Table 2 Correlation between the fiber fraction volume and characteristic parameters of the array.

\begin{tabular}{|c|c|c|c|c|c|c|c|c|c|}
\hline $\mathrm{V}_{\mathrm{f}}$ & $0.78 \%$ & $3.14 \%$ & $7.07 \%$ & $12.56 \%$ & $19.63 \%$ & $28.27 \%$ & $38.48 \%$ & $50.26 \%$ & $63.61 \%$ \\
\hline$\frac{d_{f}}{2 a}$ & 0.1 & 0.2 & 0.3 & 0.4 & 0.5 & 0.6 & 0.7 & 0.8 & 0.9 \\
\hline
\end{tabular}

A crosswise macro-stress $\sigma_{\mathrm{p}}$ is applied to a generic unit cell and maintained constant. A uniform temperature field, variable over a range 0 to $\Delta \theta_{0}$, is combined to the mechanical stress throughout the analysis (Fig. 1-b). During loading, the free edges are kept straight by imposing plane condition. The 
geometry of the array is defined by the fiber diameter $\mathrm{d}_{\mathrm{f}}$, and the fiber distance $2 \mathrm{a}$. Hence the fiber volume fraction $\mathrm{V}_{\mathrm{f}}$ can be expressed in terms of these 2 parameters as $V_{f}=\pi d_{f}^{2} / 16 a^{2}$. Correlation between $\mathrm{V}_{\mathrm{f}}$ and the geometric parameters of the array is shown in Table 2.

\section{RESULTS AND DISCUSSIONS}

The comprehensive inelastic cyclic behaviors of a unidirectional fiber reinforced MMC, have been investigated considering the effects of two different reinforcements, distinct volume fractions and various amplitudes of cyclic thermal loading. The greatest value of the fiber fraction volume is $\mathrm{V}_{\mathrm{f}}=$ $63.61 \%$. Calculations were accomplished for the following values: $\mathrm{V}_{\mathrm{f}}=0.78 \%, 3.14 \%, 7.06 \%, 12.56 \%$, $19.63 \%, 28.27 \%, 38.48 \%, 50.26 \%$ and $63.61 \%$ as shown in Table 2.

\subsection{Linear Elastic Solutions}

As a Direct Method, the Linear Matching Method has the capability to evaluate accurately the upper bounds to the shakedown and ratchet limits. The strategy is based on a simple idea of characterizing the history of stress and inelastic strain as the solution of a linear problem, where the Young's moduli are allowed to vary both spatially and during the cycle in an iterative way. The linear elastic solutions were evaluated, in the present work, with respect to the reference loads $\sigma_{\mathrm{p} 0}=80 \mathrm{Mpa}$ and $\Delta \theta_{0}=50^{\circ} \mathrm{C}$. Contours of von Mises effective stress concerning the matrix for both composites are shown in Fig. 2 for $\mathrm{V}_{\mathrm{f}}=19.63 \%$.

(a)

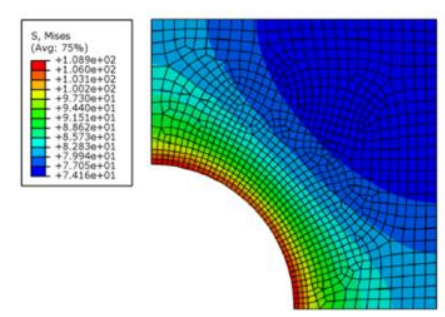

$\mathrm{Al} / \mathrm{Al}_{2} \mathrm{O}_{3}$

(b)

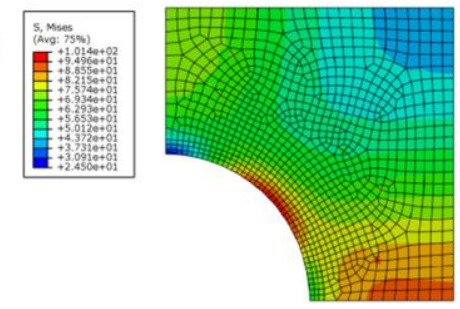

$\mathrm{Al} / \mathrm{Al}_{2} \mathrm{O}_{3}$

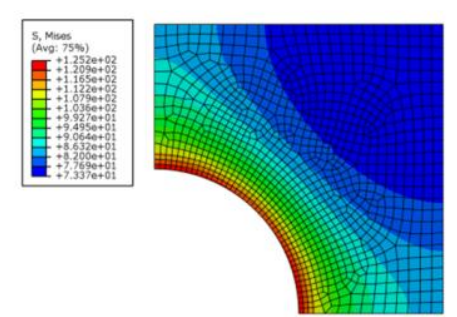

$\mathrm{Al} / \mathrm{SiC}$

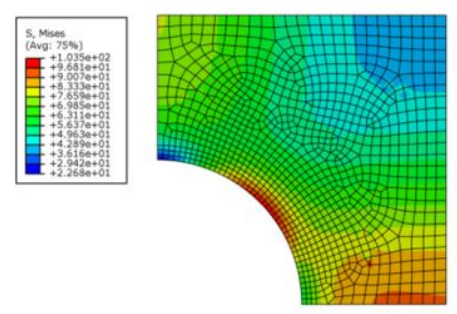

$\mathbf{A l} / \mathbf{S i C}$

Fig. 2. Effective elastic stress contours of $\mathrm{Al} / \mathrm{Al}_{2} \mathrm{O}_{3}$ and $\mathrm{Al} / \mathrm{SiC}$ composites with $\mathrm{V}_{\mathrm{f}}=19.63 \%$ subjected to (a) $\sigma_{\mathrm{p} 0}=80 \mathrm{MPa}, \Delta \theta_{0}=0^{\circ} \mathrm{C}$ and (b) $\sigma_{\mathrm{p} 0}=0, \Delta \theta_{0}=50^{\circ} \mathrm{C}$, respectively.

\subsection{Limit Analysis}

The transversal limit load, i.e. the load carrying capacity off-axis, of the AMCs subjected to the uniaxial macro-stress $\sigma_{\mathrm{p}}$ has been calculated using the LMM shakedown analysis as a special case. 


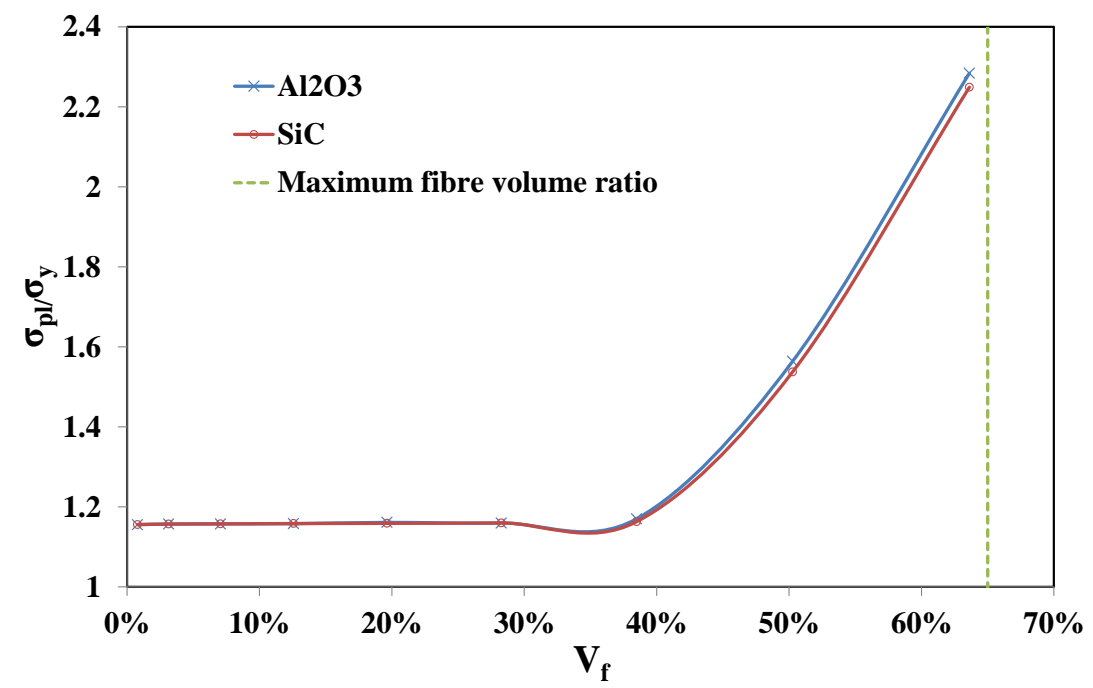

Fig. 3. Limit tension load $\sigma_{\mathrm{pl}}$ normalized to the matrix yield stress $\sigma_{\mathrm{y}}$ for $\mathrm{Al} / \mathrm{Al}_{2} \mathrm{O}_{3}$ and $\mathrm{Al} / \mathrm{SiC}$ composites.

Fig. 3 shows the variation of the limit load $\sigma_{\mathrm{pl}}$ with $\mathrm{V}_{\mathrm{f}}$ for both the $\mathrm{Al} / \mathrm{Al}_{2} \mathrm{O}_{3}$ and $\mathrm{Al} / \mathrm{S}_{\mathrm{i}} \mathrm{C}$ composites where $\sigma_{\mathrm{pl}}$ is normalized by the yield stress of aluminum material, which is equal to $80 \mathrm{MPa}$. It can be identified clearly from Fig. 3 that both alumina and silicon carbide fibers introduce the same limit load throughout the volume range analyzed. When the fiber volume fraction $\mathrm{V}_{\mathrm{f}}$ is less than $\mathrm{Vf}_{\text {ref }}$ which is equal to almost $40 \%$, the limit loads of AMCs tend to be determined by the matrix material only. When $\mathrm{V}_{\mathrm{f}}$ is greater than $40 \%$, the limit loads of AMCs increase rapidly with the increase of the fiber volume fraction, where the fiber enhanced the material endurance. A linear best fit to the limit load is given by

$$
\frac{\sigma_{p l}}{\sigma_{y}}=g_{1}\left(V_{f}\right)=\left\{\begin{array}{lr}
1.15 & 0 \% \leq V_{f} \leq 40 \% \\
8.343 V_{f}-3.024 & 40 \%<V_{f} \leq 65 \%
\end{array}\right.
$$

\subsection{Shakedown and ratchet limit}

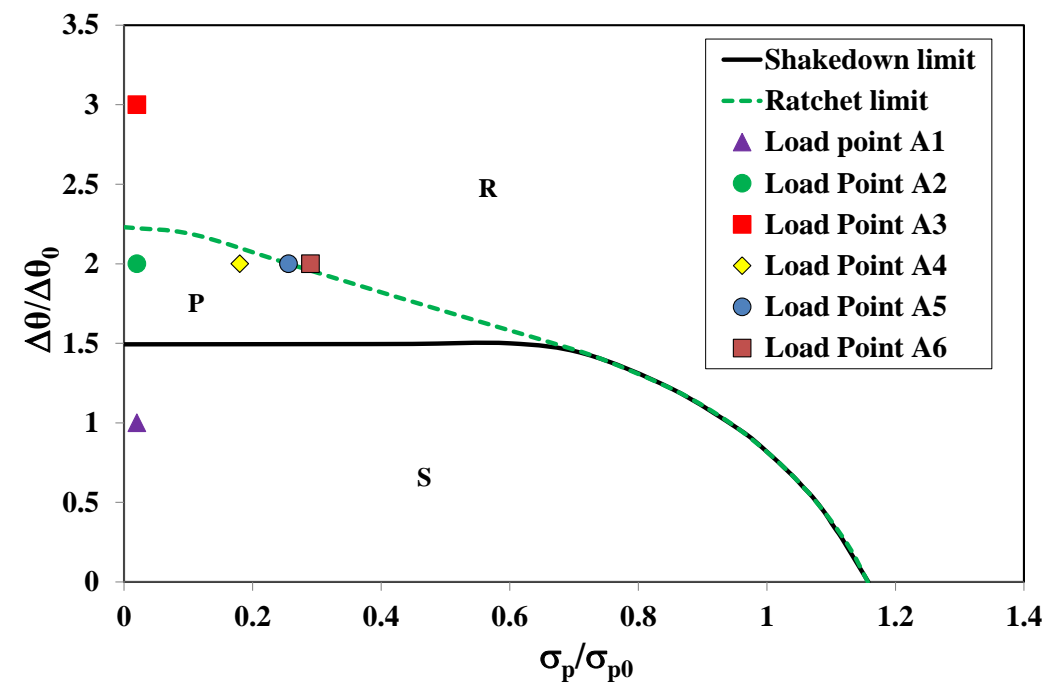

Fig. 4. Shakedown and ratchet limit boundaries for the $\mathrm{Al} / \mathrm{Al}_{2} \mathrm{O}_{3}$ composite with $\mathrm{V}_{\mathrm{f}}=12.56 \%$. 
Fig. 4 shows a typical set of shakedown and ratchet limit interaction curves for the $\mathrm{Al} / \mathrm{Al}_{2} \mathrm{O}_{3}$ composite with $\mathrm{V}_{\mathrm{f}}=12.56 \%$, where $\mathrm{S}$ stands for shakedown (and elastic) region, $\mathrm{P}$ denotes the reverse plasticity region and $\mathrm{R}$ is the ratcheting region. The axis are expressed in non-dimensional variables, $\sigma_{\mathrm{p}} / \sigma_{\mathrm{y}}$ and $\Delta \theta / \Delta \theta_{0}$ where $\Delta \theta_{0}=50^{\circ} \mathrm{C}$. Two critical design limits are indicated in Fig.4: the reverse plasticity limit $\Delta \theta_{\text {rp }}$ and ratchet limit $\Delta \theta_{\text {rtc }}$ for the MMCs subjected to the cyclic uniform temperature only. The reverse plasticity limit $\Delta \theta_{\mathrm{rp}}$ is the maximum of the cyclic thermal load range above which reverse plasticity occurs whilst $\Delta \theta_{\text {rtc }}$ is the maximum of the cyclic thermal load range above which the structure exhibits ratcheting for any constant mechanical load and leads to an incremental plastic collapse. It is important to note that for a pure cyclic thermal load condition no ratcheting occurs even if the cyclic thermal load range is greater than $\Delta \theta_{\mathrm{rtc}}$.

Table 3 Cyclic load points analysed by a set of step-by-step analysis.

\begin{tabular}{|c|c|c|c|c|}
\hline Load Case & $\boldsymbol{\Delta} \boldsymbol{\theta} / \mathbf{5 0}$ & $\boldsymbol{\sigma}_{\mathbf{p}} / \mathbf{8 0}$ & $\boldsymbol{\Delta} \boldsymbol{\theta}\left({ }^{\circ} \mathrm{C}\right)$ & $\boldsymbol{\sigma}_{\mathbf{p}}(\mathbf{M P a})$ \\
\hline $\mathrm{A} 1$ & 1 & 0.02 & 50 & 1.60 \\
\hline $\mathrm{A} 2$ & 2 & 0.02 & 100 & 1.60 \\
\hline $\mathrm{A} 3$ & 3 & 0.02 & 150 & 1.60 \\
\hline $\mathrm{A} 4$ & 2 & 0.18 & 100 & 14.40 \\
\hline $\mathrm{A} 5$ & 2 & 0.256 & 100 & 20.48 \\
\hline $\mathrm{A} 6$ & 2 & 0.29 & 100 & 23.20 \\
\hline
\end{tabular}

In order to deep understand the mechanism and validate the shakedown and ratchet limit boundaries calculated by the LMM, six cyclic load conditions as indicated by cyclic load points A1, A2, A3, A4, A5 and A6 in Fig.4 are analyzed by Abaqus step-by-step analyses and described in Table 3. The obtained histories of plastic strain magnitude PEMAG are given in Fig. 5. It can be seen clearly from Fig. 5 that as indicated by the Fig. 4, the cyclic load point A1 within the S region exhibits a shakedown mechanism, and the cyclic load points $\mathrm{A} 2$ and $\mathrm{A} 4$ within the $\mathrm{P}$ region exhibit a reverse plasticity mechanism where the PEMAG fluctuates but doesn't grow. For the cyclic load points A3, A5 and A6 which are either on the ratchet limit boundary or within the R region, the plastic strain magnitude increases rapidly and indicates a strong ratcheting mechanism.

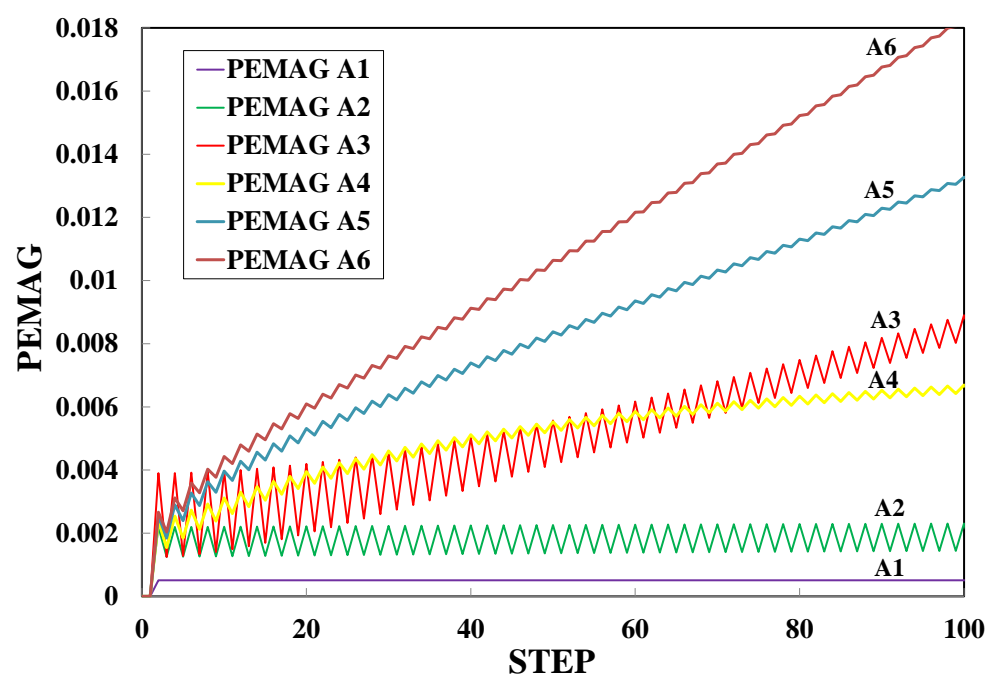

Fig. 5. History of plastic strain magnitude for the cyclic load point A1, A2, A3, A4, A5 and A6, defined in Fig.4 and evaluated by a set of step-by-step analysis. 


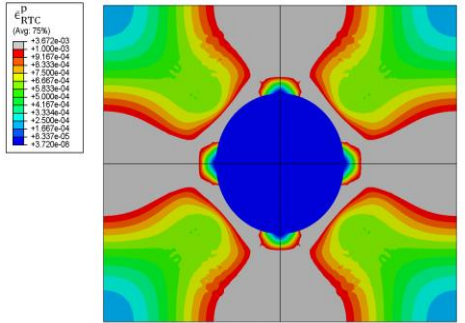

A3

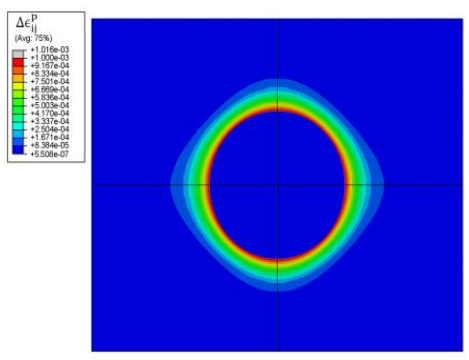

A2

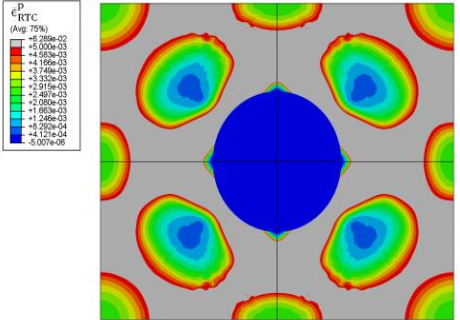

A6

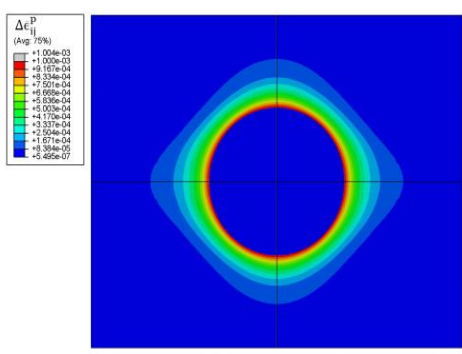

A4

Fig. 6. Contours of effective ratcheting strain for the cyclic load points $\mathrm{A} 3$ and $\mathrm{A} 6$, and plastic strain range for the cyclic load points $\mathrm{A} 2$ and $\mathrm{A} 4$, for the $\mathrm{A} 1 / \mathrm{Al}_{2} \mathrm{O}_{3}$ composite with $\mathrm{V}_{\mathrm{f}}=12.56 \%$.

Contours of effective ratchet strain $\bar{\varepsilon}_{R T C}^{p}$ for the cyclic load points A3 and A6 in ratcheting region and the plastic strain range $\Delta \bar{\varepsilon}_{i j}^{p}$ for the points A2 and A4 within the reverse plasticity region are also shown in Fig. 6. It can be observed that the ratcheting mechanism owing to a high thermal load and a small mechanical load (point A3) is different from that with a smaller thermal load and higher mechanical load (point A6) in terms of effective ratcheting strain. For the cyclic load points A2 and A4, the composite exhibits a local reverse plasticity mechanism which may leads to a low cycle fatigue failure. However due to the larger constant mechanical load, the cyclic load point A4 produces slightly larger plastic strain range around the interface comparing with the cyclic load point A2.

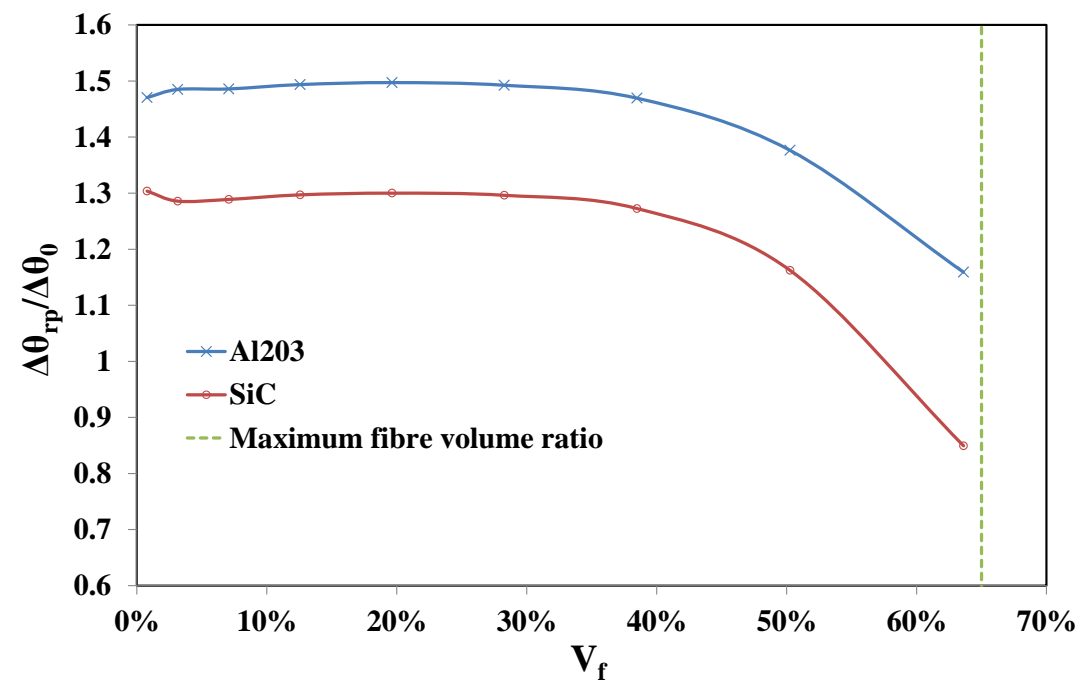

Fig. 7. Comparison of reverse plasticity limit $\Delta \theta_{\text {rp }}$ between the composites $A 1 / \mathrm{Al}_{2} \mathrm{O}_{3}$ and $\mathrm{Al} / \mathrm{S}_{\mathrm{i}} \mathrm{C}$. 


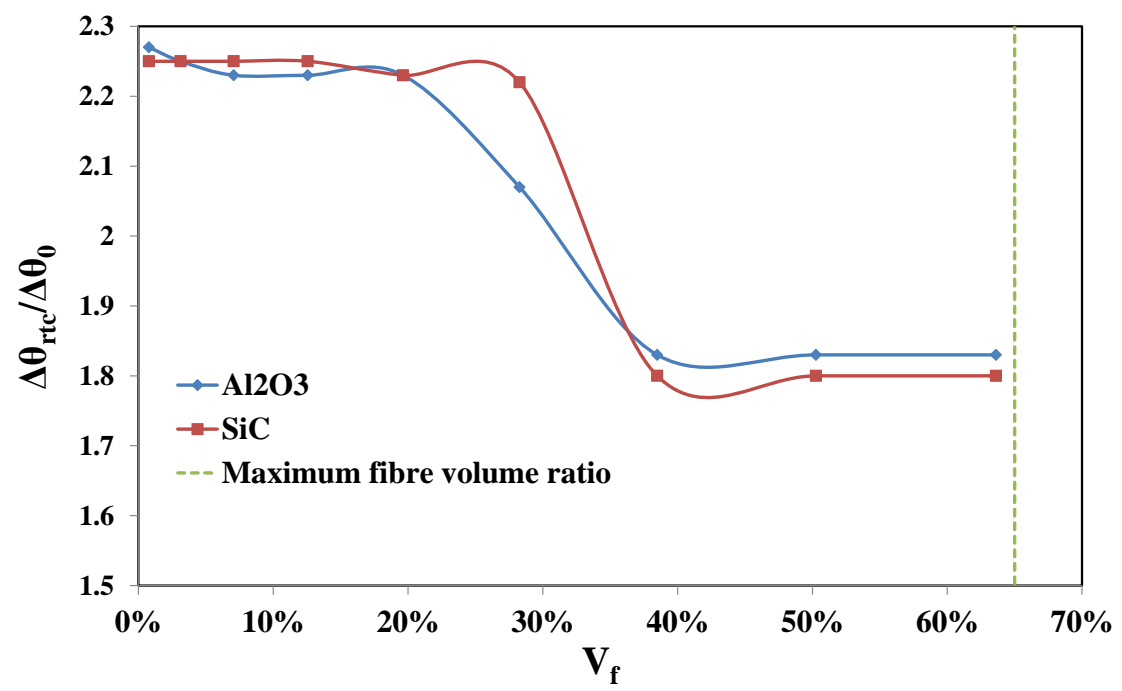

Fig. 8. Comparison of ratchet limit $\Delta \theta_{\mathrm{rtc}}$ between the composites $\mathrm{Al} / \mathrm{Al}_{2} \mathrm{O}_{3}$ and $\mathrm{Al} / \mathrm{S}_{\mathrm{i}} \mathrm{C}$.

Figs. 7 and 8 present the magnitudes of the reverse plasticity limit $\Delta \theta_{\mathrm{rp}}$ and ratchet limit $\Delta \theta_{\mathrm{rtc}}$ for the entire range of fiber volume faction $\mathrm{V}_{\mathrm{f}}$ for both the $\mathrm{Al} / \mathrm{Al}_{2} \mathrm{O}_{3}$ and $\mathrm{Al} / \mathrm{S}_{\mathrm{i}} \mathrm{C}$ composites. It can be observed that the variation of the reverse plasticity limit $\Delta \theta_{\mathrm{rp}}$ with $\mathrm{V}_{\mathrm{f}}$ shown in Fig. 7 exhibits the same trend but with slightly different magnitudes between the two fibers whilst the variation of ratchet limit $\Delta \theta_{\text {rtc }}$ shown in Fig. 8 remain almost the same.

It can also be noticed from Fig.7 that the reverse plasticity limit $\Delta \theta_{\mathrm{rp}}$ tends to remain stable until $40 \%$ of the volume fraction even if it decreases with the volume fraction when $\mathrm{V}_{\mathrm{f}}>40 \%$. Fig.8 shows that the ratchet limit $\Delta \theta_{\mathrm{rtc}}$ remains constant for the smaller fiber volume fraction $\left(\mathrm{V}_{\mathrm{f}}<20 \%\right)$ and the larger fiber volume fraction $\left(\mathrm{V}_{\mathrm{f}}>40 \%\right)$, but with a reduction in the magnitude when $\mathrm{V}_{\mathrm{f}}$ increases from $20 \%$ to $40 \%$. It is worth noting that the reverse plasticity limit $\Delta \theta_{\mathrm{rp}}$ is determined by the local maximum thermal stress range at the material interface due to the significant difference in the coefficient of thermal expansion between fiber and matrix materials. For the ratchet limit $\Delta \theta_{\mathrm{rtc}}$, the local thermal stress caused by the material mismatch does not have significant effect. The ratchet limit is governed by a global failure mechanism, which is mainly determined by the combined action of the constant mechanical load and the affected area of the thermal stress on the matrix material. Only when the fiber volume fraction is large enough, the local cyclic thermal stress due to the material mismatch starts to play an important role as the effect of the thermal stress becomes global mechanism.

A linear fit to both the reverse plastic limit and ratchet limit is given by equations (12) and (13) respectively;

$$
\begin{gathered}
\frac{\Delta \theta_{r p}}{\Delta \theta_{0}}=g_{2}\left(V_{f}\right)=\left\{\begin{array}{lr}
1.47 & 0 \% \leq V_{f} \leq 40 \% \\
-1.246 V_{f}+1.97 & 40 \%<V_{f} \leq 65 \%
\end{array}\right. \\
\frac{\Delta \theta_{r t c}}{\Delta \theta_{0}}=g_{3}\left(V_{f}\right)=\left\{\begin{array}{lr}
2.25 & 0 \% \leq V_{f} \leq 20 \% \\
-2.234 V_{f}+2.688 & 20 \%<V_{f} \leq 40 \% \\
1.83 & 40 \%<V_{f} \leq 65 \%
\end{array}\right.
\end{gathered}
$$




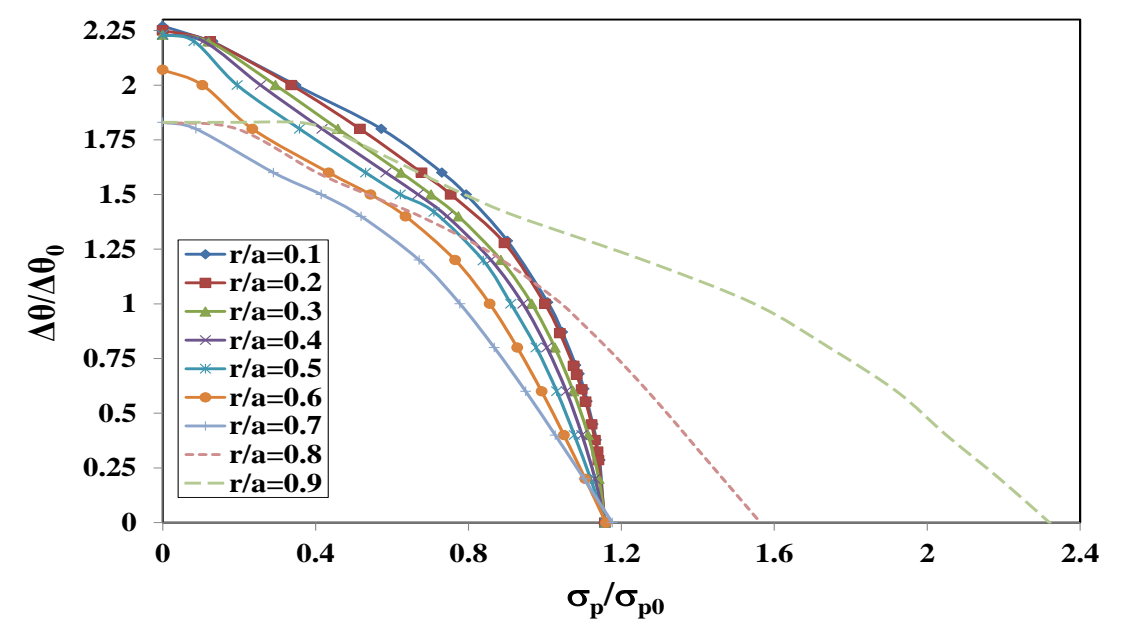

Fig. 9. Variation of the ratchet boundaries with the ratio r/a for the composite $A 1 / \mathrm{Al}_{2} \mathrm{O}_{3}$.

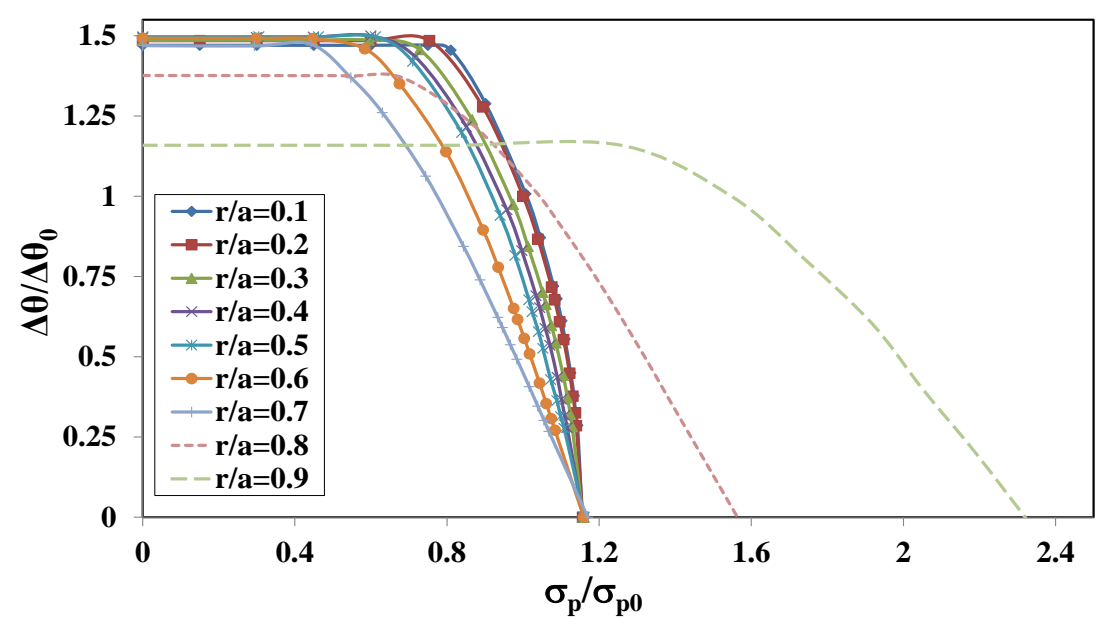

Fig. 10. Variation of the shakedown boundaries with the ratio r/a for the composite $A 1 / \mathrm{Al}_{2} \mathrm{O}_{3}$.

Figs. 9 and 10 show the complete set of limits for the composite $\mathrm{Al} / \mathrm{Al}_{2} \mathrm{O}_{3}$. Since there is a correlation between the fiber fraction volume and the characteristic parameters of the array (Table 2), the limit boundaries are presented in terms of the ratio r/a.

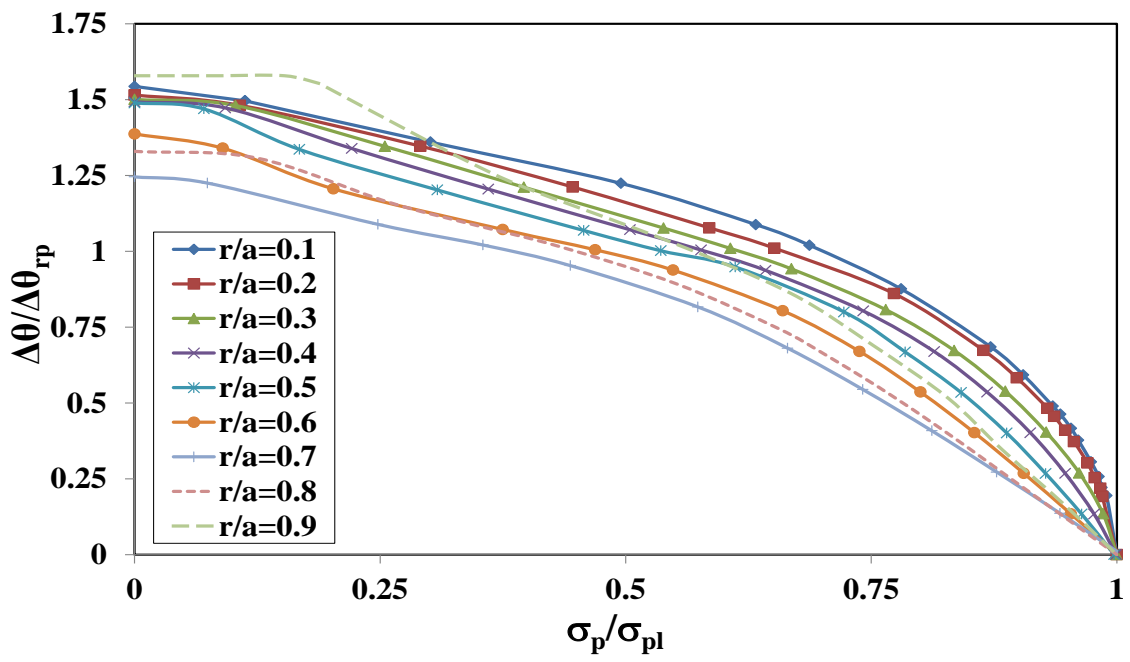

Fig. 11. Variation of the relative ratchet boundaries with the ratio $r / a$ for the composite $A 1 / \mathrm{Al}_{2} \mathrm{O}_{3}$. 


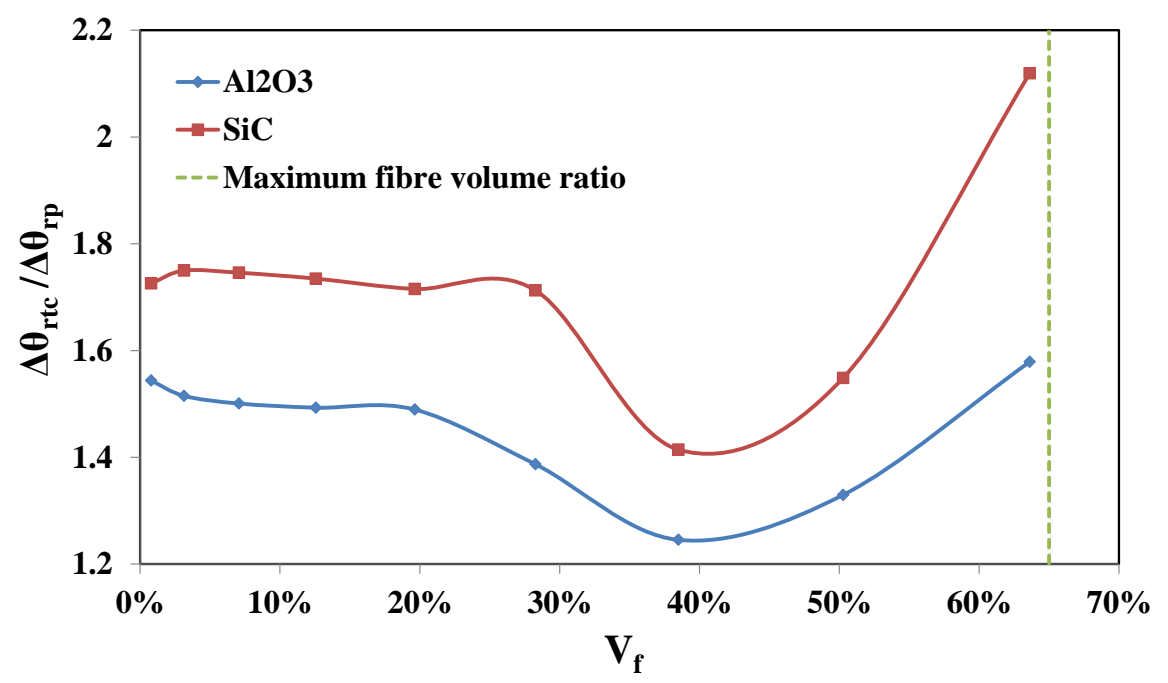

Fig. 12. Comparison of relative ratchet limit between the composites $\mathrm{Al} / \mathrm{Al}_{2} \mathrm{O}_{3}$ and $\mathrm{Al} / \mathrm{S}_{\mathrm{i}} \mathrm{C}$.

The complete set of ratchet limits for the composite $\mathrm{Al} / \mathrm{Al}_{2} \mathrm{O}_{3}$ can also be expressed in terms of relative parameters and it is depicted in Fig. 11. In other words, temperature range $\Delta \theta$ has been normalized by the reverse plasticity limit $\Delta \theta_{\text {rp }}$ whilst the constant mechanical load $\sigma_{\mathrm{p}}$ by the limit load $\sigma_{\mathrm{pl}}$. With this format, the reverse plasticity zone corresponds to the ratio $\Delta \theta / \Delta \theta_{\mathrm{rp}}>1$. Fig.12 presents the comparison of the nondimensional critical ratchet limit $\Delta \theta_{\text {rtc }}$ with respect to $\Delta \theta_{\text {rp }}$ for different values of $\mathrm{V}_{\mathrm{f}}$ between the composites $\mathrm{Al} / \mathrm{Al}_{2} \mathrm{O}_{3}$ and $\mathrm{Al} / \mathrm{S}_{\mathrm{i}} \mathrm{C}$. This relative ratchet limit corresponds to the ratio $\Delta \theta_{\mathrm{rtc}} / \Delta \theta_{\mathrm{rp}}$ when $\sigma_{\mathrm{p}}$ is equal to 0 . It is worth noting that for a higher value of $\Delta \theta_{\mathrm{rtc}} / \Delta \theta_{\mathrm{rp}}$ the structure can safely undergo a higher cyclic thermal load $\Delta \theta$ without exhibiting ratcheting. Therefore the composite $\mathrm{Al} / \mathrm{S}_{\mathrm{i}} \mathrm{C}$ shows a better capacity to prevent incremental plastic collapse compared with the composite $\mathrm{Al} / \mathrm{Al}_{2} \mathrm{O}_{3}$.

\subsection{Plastic Strain Range and Ratcheting Strain}

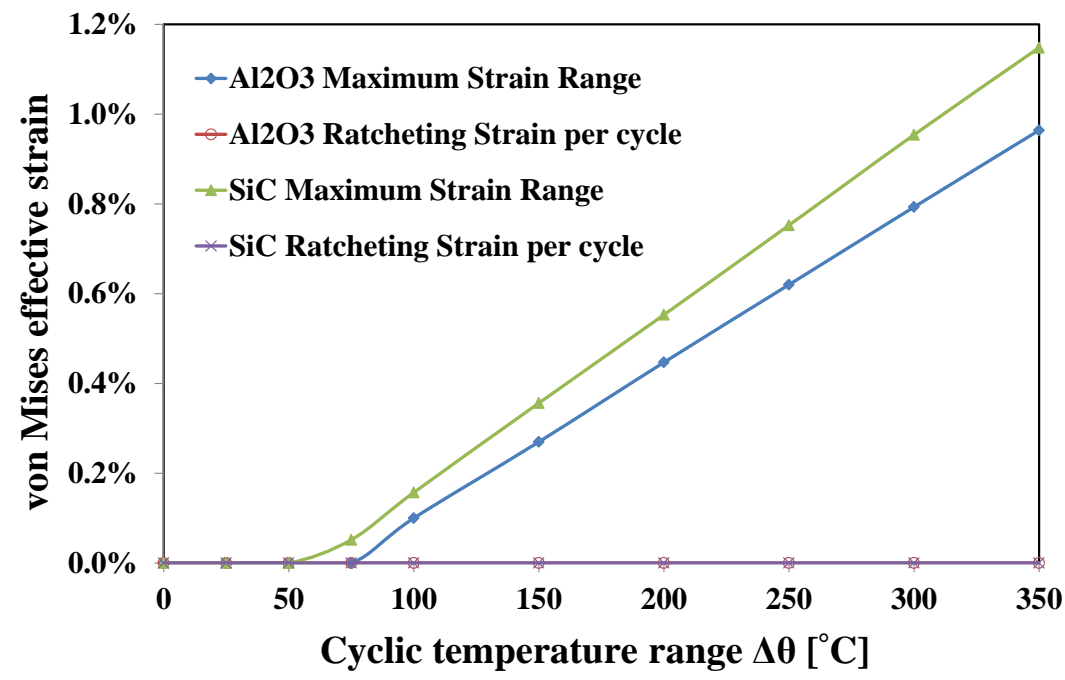

Fig. 13. Maximum plastic strain ranges and ratcheting strains per cycle of the $\mathrm{Al} / \mathrm{Al}_{2} \mathrm{O}_{3}$ and $\mathrm{Al} / \mathrm{S}_{\mathrm{i}} \mathrm{C}$ composites subjected to a wide range of varying cyclic thermal loads $\Delta \theta$ and constant $\sigma_{\mathrm{p}}=0 \mathrm{MPa}\left(\mathrm{V}_{\mathrm{f}}\right.$ $=12.56 \%$ ). 


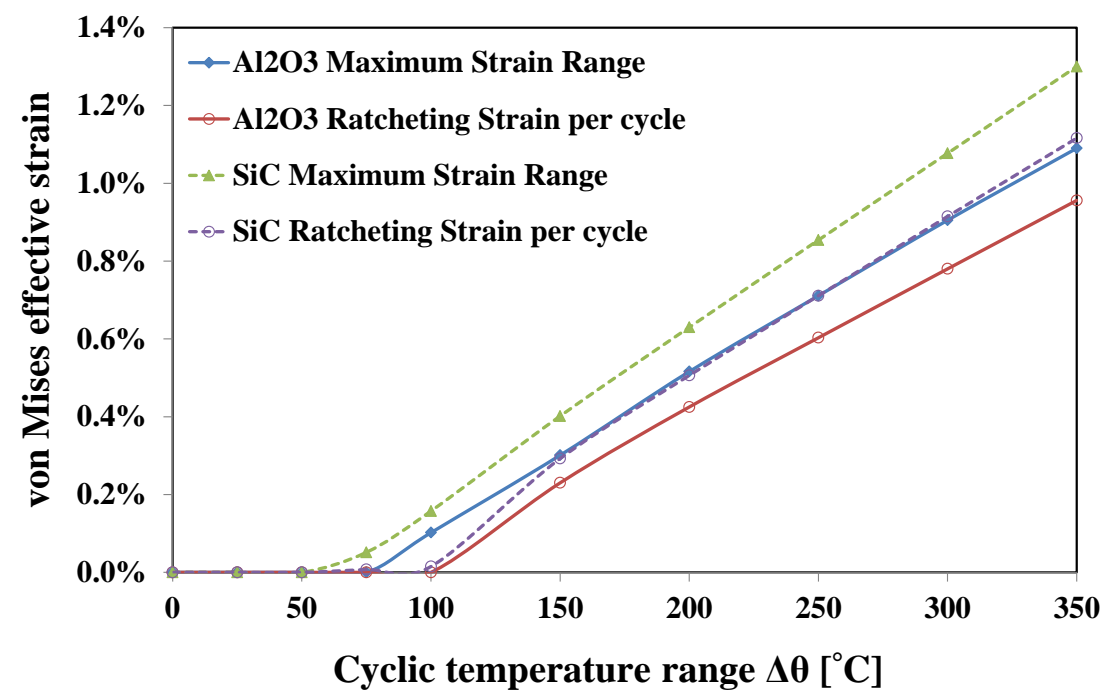

Fig. 14. Maximum plastic strain ranges and ratcheting strains per cycle of the $\mathrm{Al} / \mathrm{Al}_{2} \mathrm{O}_{3}$ and $\mathrm{Al} / \mathrm{S}_{\mathrm{i}} \mathrm{C}$ composites subjected to a wide range of varying cyclic thermal loads $\Delta \theta$ and constant $\sigma_{\mathrm{p}}=20 \mathrm{MPa}\left(\mathrm{V}_{\mathrm{f}}\right.$ $=12.56 \%$ ).

A composite structure with no thermal gradients can experience large internal thermal strains due to the different nature of its constituents. As pointed out in the previous paragraph, the difference in coefficients of thermal expansion between the fibre and the matrix, affects the reverse plasticity limit $\Delta \theta_{\text {rp }}$ i.e. the LCF behaviour. Therefore the relative value between these coefficients is the crucial property that influences in direct proportionality the thermal strains that are induced by either thermal or thermo-mechanical fatigue loadings (Jansson and Leckif, 1992). In such conditions, the matrix may undergo large internal inelastic deformations, potentially leading to internal crack initiation. Fiber/Matrix debonding is also common, and gross macroscopic ratcheting deformation of the composite has been reported (Ahmadzadeh and Varvani-Farahani, 2015; Jansson and Leckif, 1992).

The thermal degradation of matrix yield strength $\sigma_{\mathrm{y}}$ is also a crucial aspect since it directly affects the reverse plasticity limit $\Delta \theta_{\mathrm{rp}}$, the ratchet limit $\Delta \theta_{\mathrm{rtc}}$ as well as the interaction diagrams shown in figs. 9 and 10. It has been reported that a lower value of $\sigma_{\mathrm{y}}$ leads to a lower values of the critical design limits mentioned (Chen, 2010). Therefore neglecting such temperature dependency leads to a less conservative approach in the evaluation of both plastic strain range $\Delta \bar{\varepsilon}_{\max }^{p}$ and ratcheting strain per cycle $\Delta \bar{\varepsilon}_{R T C}^{p}$. However, the choice to investigate different aspects of CFAMCs urged the authors to employ temperature independent material parameters despite the capability of the LMM to address this dependency.

The thermal fatigue response of CFAMCs has been investigated considering two load conditions. The unit cell has been subjected to varying cyclic thermal loading $\Delta \theta$ with and without transversal mechanical load. In the former condition the uniaxial macro stress $\sigma_{\mathrm{p}}=20.5 \mathrm{MPa}$ is employed to investigate the off-axis ratcheting behaviour.

Figs. 13 and 14 present the calculated maximum von Mises plastic strain range $\Delta \bar{\varepsilon}_{\max }^{p}$ and ratcheting strain per cycle $\Delta \bar{\varepsilon}_{\text {RTC }}^{p}$ by the LMM for both the composite $\mathrm{Al}_{1} / \mathrm{Al}_{2} \mathrm{O}_{3}$ and $\mathrm{Al} / \mathrm{SiC}$ $\left(\mathrm{V}_{\mathrm{f}}=12.56 \%\right)$ subjected to varying cyclic thermal loads $\Delta \theta$ and constant $\sigma_{\mathrm{p}}=0$ and $20.5 \mathrm{MPa}$, respectively. It can be identified that the magnitude of the $\Delta \bar{\varepsilon}_{\text {max }}^{p}$ and $\Delta \bar{\varepsilon}_{\text {RTC }}^{p}$ for each cyclic temperature range is higher for the composite $\mathrm{Al} / \mathrm{S}_{\mathrm{i}} \mathrm{C}$ than $\mathrm{Al} / \mathrm{Al}_{2} \mathrm{O}_{3}$. All these plastic strain range and ratcheting strain solutions have been verified by the Abaqus step-by-step analysis, which produces nearly identical results comparing with the LMM, with an error less than $1 \%$. 
The coincidence of the LMM and Abaqus step-by-step analysis results in Figs. 13 and 14 confirms the accuracy of the LMM. However, comparing with the LMM, the Abaqus step-by-step analysis involves much more significant computer effort to produce the same results. It is also observed that there is no ratcheting for any cyclic thermal loads when the uniaxial macro stress $\sigma_{\mathrm{p}}=0$. However, when $\sigma_{\mathrm{p}}=20.5 \mathrm{MPa}$, the ratcheting strain occurs when the cyclic uniform temperature range $\Delta \theta / \Delta \theta_{0}$ is greater than ratchet limit, which equals to 2 according to the interaction diagram (Fig. 4) for $\mathrm{V}_{\mathrm{f}}=12.56 \%$. The most interesting observation from Figs. 13 and 14 is that the magnitude of maximum plastic strain range concerning the fatigue crack initiation not only depends upon the varying cyclic thermal loads $\Delta \theta$, but is also affected by the constant uniaxial macro-stress $\sigma_{\mathrm{p}}$. The mild increase of $\Delta \overline{\mathcal{E}}_{\text {max }}^{p}$ as well as the existence of $\Delta \bar{\varepsilon}_{\text {RTC }}^{p}$ due to the presence of the constant uniaxial macro-stress agrees very well with the general experimental observations (Ahmadzadeh and Varvani-Farahani, 2015; Jansson and Leckif, 1992).

Although the maximum von Mises plastic strain ranges are different for the composites $\mathrm{Al} / \mathrm{S}_{\mathrm{i}} \mathrm{C}$ and $\mathrm{Al} / \mathrm{Al}_{2} \mathrm{O}_{3}$ subjected to the pure cyclic thermal loads as shown in Fig. 13, a unified plot of the maximum plastic strain range for both composites can be presented in Fig. 15 in terms of the ratio $\Delta \sigma^{\theta} / \Delta \sigma_{r p}^{\theta}$ where $\Delta \sigma^{\theta}$ denotes the maximum effective elastic thermal stress corresponding to a temperature change $\Delta \theta$ whilst $\Delta \sigma_{r p}^{\theta}$ is a fixed value and it is equal to twice the yield stress of the matrix $\sigma_{\mathrm{y}}$.

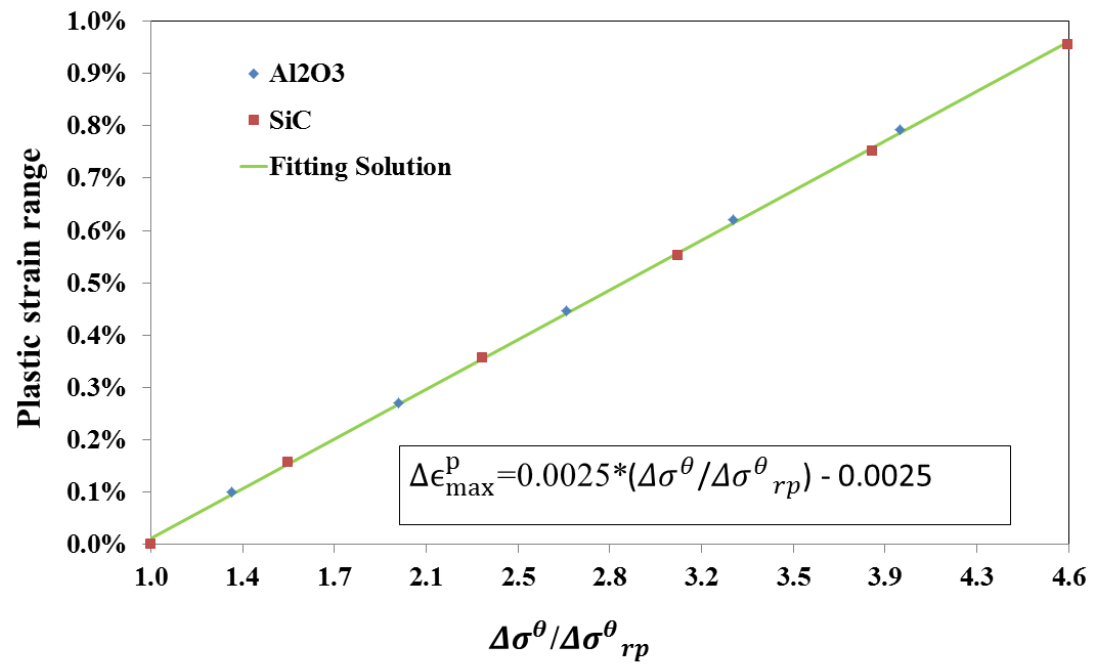

Fig. 15. Unified maximum plastic strain ranges $\Delta \bar{\varepsilon}_{\text {max }}^{p}$ for the low cycle fatigue assessment of both the $\mathrm{Al} / \mathrm{Al}_{2} \mathrm{O}_{3}$ and $\mathrm{Al} / \mathrm{S}_{\mathrm{i}} \mathrm{C}$ composites subjected to a wide range of varying cyclic thermal loads for $\mathrm{V}_{\mathrm{f}}$ $=12.56 \%$.

It can be observed clearly from Fig. 15 that for both the fibers, the plastic strain range occurs when the maximum elastic thermal stress range $\Delta \sigma^{\theta}$ is greater than $2 \sigma_{\mathrm{y}}$. For the same temperature range $\Delta \theta$, the maximum elastic thermal stress range $\Delta \sigma^{\theta}$ would be different for the composites $\mathrm{Al} / \mathrm{S}_{\mathrm{i}} \mathrm{C}$ and $\mathrm{Al} / \mathrm{Al}_{2} \mathrm{O}_{3}$ due to the different coefficients of thermal expansion of fiber materials. The calculated maximum plastic strain range can be represented by a unified linear fitting solution as shown in Fig.15, where the ratio $\Delta \sigma^{\theta} / \Delta \sigma_{r p}^{\theta}$ is a function of the applied cyclic temperature range $\Delta \theta$ : 


$$
\frac{\Delta \sigma^{\theta}}{\Delta \sigma_{r p}^{\theta}}=\frac{\Delta \theta}{\Delta \theta_{r p}}
$$

where the temperature $\Delta \theta_{r p}$ when $\mathrm{V}_{\mathrm{f}}=12.56 \%$ is equal to $74.68^{\circ} \mathrm{C}$ for the composite $\mathrm{Al}_{2} / \mathrm{Al}_{2} \mathrm{O}_{3}$ and $64.85^{\circ} \mathrm{C}$ for the composite $\mathrm{Al} / \mathrm{S}_{\mathrm{i}} \mathrm{C}$.

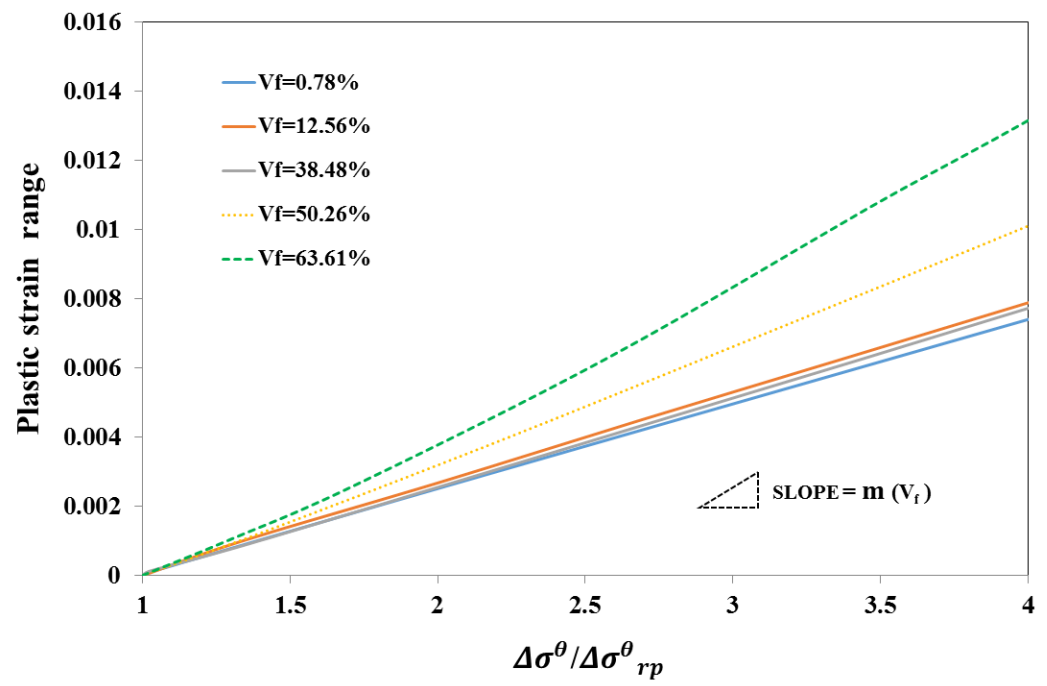

Fig. 16. Unified maximum plastic strain ranges $\Delta \bar{\varepsilon}_{\text {max }}^{p}$ for both $\mathrm{Al} / \mathrm{Al}_{2} \mathrm{O}_{3}$ and $\mathrm{Al} / \mathrm{SiC}$ composites subjected to a wide range of varying cyclic thermal loads for different values of $\mathrm{V}_{\mathrm{f}}$.

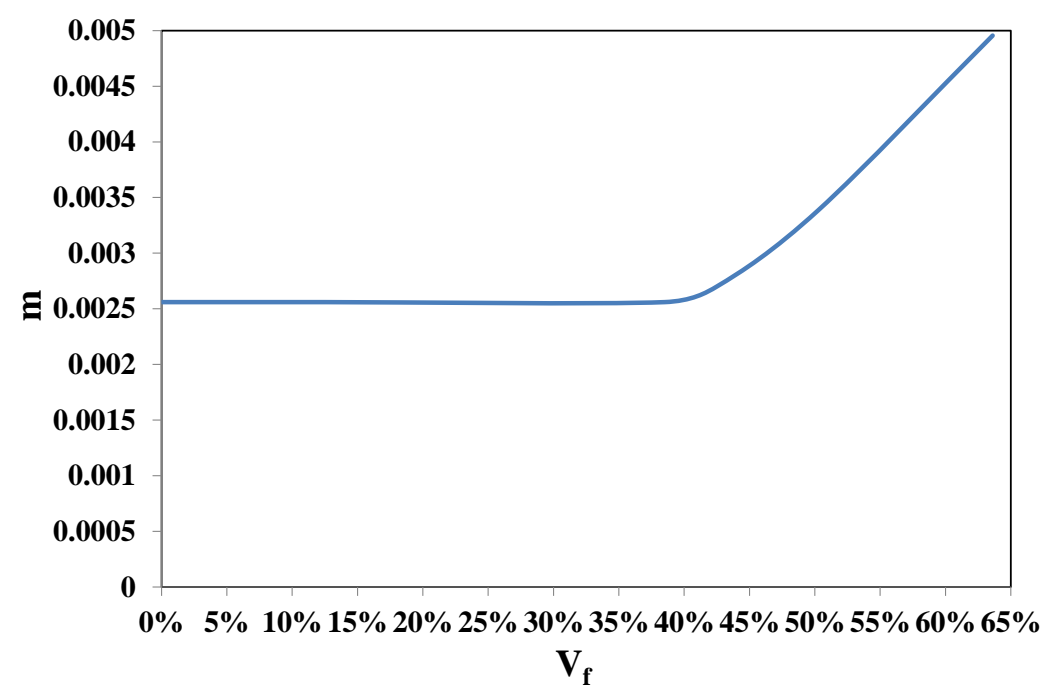

Fig. 17. Variation of the slope $m$ with the volume fraction $\mathrm{V}_{\mathrm{f}}$ for $\mathrm{Al} / \mathrm{Al}_{2} \mathrm{O}_{3}$ and $\mathrm{Al} / \mathrm{S}_{\mathrm{i}} \mathrm{C}$ composites concerning the straight lines shown in Fig. 16.

Extending the previous result to different values of fraction volume, it is possible to evaluate the variation of the maximum plastic strain range with the ratio $\Delta \sigma^{\theta} / \Delta \sigma_{r p}^{\theta}$ by a set of straight lines characterized by the point $(1,0)$ and their slopes that are function of $V_{f}$ (Fig. 16). Defining as $m\left(V_{f}\right)$ the fraction volume dependent slope, its variation throughout the range of $\mathrm{V}_{\mathrm{f}}$ analyzed is given in Fig. 17. It is worth nothing that when $\mathrm{V}_{\mathrm{f}}$ is less than $38.48 \%, \mathrm{~m}$ is almost constant and equal to 0.00256 whilst for a $\mathrm{V}_{\mathrm{f}}$ greater than $38.48 \%$ an increase of $\mathrm{m}$ is noticed. A best fit to the angular coefficient is given by: 


$$
\left\{\begin{array}{lr}
m\left(V_{f}\right)=0.00256 & 0 \leq V_{f} \leq 0.3848 \\
m\left(V_{f}\right)=-0.1251 V_{f}^{3}+0.2095 V_{f}^{2}-0.1046 V_{f}+0.0189 & 0.3848<V_{f} \leq 0.6361
\end{array}\right.
$$

A general equation for the evaluation of the maximum plastic strain range $\Delta \bar{\varepsilon}_{\text {max }}^{p}$ for $\mathrm{Al} / \mathrm{Al}_{2} \mathrm{O}_{3}$ and $\mathrm{Al} / \mathrm{S}_{\mathrm{i}} \mathrm{C}$ composites can be provided as function of both $\Delta \sigma^{\theta} / \Delta \sigma_{r p}^{\theta}$ and $\mathrm{V}_{\mathrm{f}}$ :

$$
\Delta \varepsilon_{R P}^{p}\left(V_{f}, \Delta \sigma^{\theta} / \Delta \sigma_{r p}^{\theta}\right)=m\left(V_{f}\right) *\left[\left(\Delta \sigma^{\theta} / \Delta \sigma_{r p}^{\theta}\right)-1\right]
$$

\section{CONCLUSIONS}

The cyclic plastic behavior of unidirectional fiber-reinforced AMC's under off-axis macro stress and thermal cycling conditions has been investigated using the powerful LMM and software tool. The proposed micromechanical model, with a circular cross section and square array of fibers, efficiently predicts the effect of the reinforcement volume fraction on the load-bearing capacity, shakedown and ratcheting. Two common reinforcements, alumina and silicon carbide embedded in an elastic-perfectly plastic aluminum matrix were employed throughout the analysis. It has been demonstrated in this paper that when the fiber volume fraction is greater than $40 \%$, the load carrying capacity of the AMCs greatly increases. However this slightly reduces the maximum cyclic thermal load range above which reverse plasticity occurs, as well as the maximum cyclic thermal load range above which ratcheting occurs for any constant mechanical load.

In addition, both the plastic strain ranges and ratcheting strains of the $\mathrm{Al} / \mathrm{Al}_{2} \mathrm{O}_{3}$ and $\mathrm{Al} / \mathrm{S}_{\mathrm{i}} \mathrm{C}$ composites subjected to a wide range of cyclic uniform temperatures have been calculated. A general unified formula for evaluating the maximum plastic strain ranges for the low cycle fatigue assessment of both the $\mathrm{Al} / \mathrm{Al}_{2} \mathrm{O}_{3}$ and $\mathrm{Al} / \mathrm{S}_{\mathrm{i}} \mathrm{C}$ composites has also been proposed. The minimal increase of the plastic strain range due to the combined effect of the constant uniaxial macro-stress with the cyclic uniform temperatures has also been verified.

The ratchet boundaries calculated by the LMM provide a clear understanding of the ratcheting failure mechanism, demonstrating that the increase of the plastic strain is even due to large thermal amplitudes and small applied macro stress, which comply with the general experimental observations.

A set of step-by-step analyses were carried out in order to provide a validation of the LMM's results in terms of both accuracy and CPU time. All the results presented in this paper prove that it is possible to efficiently characterize the cyclic plastic behavior of MMCs with the use of the Linear Matching Method.

\section{ACKNOWLEDGEMENTS}

The authors gratefully acknowledge the support of the University of Strathclyde and Royal Academy of Engineering during the course of this work. The authors also thank the ICCM20 conference in Copenhagen for presenting part of research outcomes from this study. 


\section{REFERENCES}

Ahmadzadeh, G., Varvani-Farahani, A., 2015. Ratcheting prediction of Al 6061/SiCP composite samples under asymmetric stress cycles by means of the Ahmadzadeh-Varvani hardening rule. Journal of Composite Materials, 0021998315604037.

Chen, H., 2010. Lower and upper bound shakedown analysis of structures with temperaturedependent yield stress. Journal of Pressure Vessel Technology 132, 011202.

Chen, H., Ponter, A.R., 2001. A method for the evaluation of a ratchet limit and the amplitude of plastic strain for bodies subjected to cyclic loading. European Journal of MechanicsA/Solids 20, 555-571.

Chen, H., Ponter, A.R., 2005. On the behaviour of a particulate metal matrix composite subjected to cyclic temperature and constant stress. Computational materials science 34, 425441.

Chen, H., Ponter, A.R., 2010. A direct method on the evaluation of ratchet limit. Journal of Pressure Vessel Technology 132, 041202.

Chen, H., Ure, J., Tipping, D., 2014. Integrated structural analysis tool using the Linear Matching Method part 2-Application and verification. International Journal of Pressure Vessels and Piping 120, 152-161.

Davis, L., Andres, C., Allison, J., 1998. Microstructure and strengthening of metal matrix composites. Materials Science and Engineering: A 249, 40-45.

Dvorak, G., Bahel-el-Din, Y., Macheret, Y., Liu, C., 1988. An experimental study of elasticplastic behavior of a fibrous boron-aluminum composite. Journal of the Mechanics and Physics of Solids 36, 655-687.

Farrissey, L., Schmauder, S., Dong, M., Soppa, E., Poech, M., McHugh, P., 1999. Investigation of the strengthening of particulate reinforced composites using different analytical and finite element models. Computational materials science 15, 1-10.

Ge, D., Gu, M., 2001. Mechanical properties of hybrid reinforced aluminum based composites. Materials Letters 49, 334-339.

Han, W., Eckschlager, A., Böhm, H.J., 2001. The effects of three-dimensional multi-particle arrangements on the mechanical behavior and damage initiation of particle-reinforced MMCs. Composites science and technology 61, 1581-1590.

Hibbitt, K., 1997. ABAQUS: User's Manual. Hibbitt, Karlsson \& Sorensen, Incorporated.

Jansson, S., Leckif, F., 1992. Mechanical behavior of a continuous fiber-reinforced aluminum matrix composite subjected to transverse and thermal loading. Journal of the Mechanics and Physics of Solids 40, 593-612.

Kang, G., Guo, S., Dong, C., 2006. Numerical simulation for uniaxial cyclic deformation of discontinuously reinforced metal matrix composites. Materials Science and Engineering: A 426, 66-76.

Ponter, A., 2001. Shakedown limits for a metal matrix composite. Journal of Composites, Technology and Research 23, 197-204.

Ponter, A., Leckie, F., 1998a. Bounding properties of metal-matrix composites subjected to cyclic thermal loading. Journal of the Mechanics and Physics of Solids 46, 697-717.

Ponter, A., Leckie, F., 1998b. On the behaviour of metal matrix composites subjected to cyclic thermal loading. Journal of the Mechanics and Physics of Solids 46, 2183-2199.

Suryanarayanan, K., Praveen, R., Raghuraman, S., 2013. Silicon carbide reinforced aluminium metal matrix composites for aerospace applications: a literature review. International Journal of Innovative Research in Science, Engineering and Technology 2, 6336-6344.

Tarn, J., Dvorak, G., Rao, M., 1975. Shakedown of unidirectional composites. International Journal of Solids and Structures 11, 751-764. 
Teply, J.L., Dvorak, G.J., 1988. Bounds on overall instantaneous properties of elastic-plastic composites. Journal of the Mechanics and Physics of Solids 36, 29-58.

Ure, J., Chen, H., Tipping, D., 2014. Integrated structural analysis tool using the linear matching method part 1-Software development. International Journal of Pressure Vessels and Piping 120, 141-151.

Zhang, F., Sun, P., Li, X., Zhang, G., 2001. A comparative study on microplastic deformation behavior in a $\mathrm{SiCp} / 2024 \mathrm{Al}$ composite and its unreinforced matrix alloy. Materials Letters 49, 69-74.

Zhang, H., Anderson, P., 1994. Analysis of thermally induced stress and strain in continuous fiber-reinforced composites. Metallurgical and Materials Transactions A 25, 415-425.

Zhang, H., Daehn, G.S., Wagoner, R., 1990. The temperature-cycling deformation of particle reinforced metal matrix composites-A finite element study. Scripta metallurgica et materialia 24, 2151-2155.

Zhang, H., Daehn, G.S., Wagoner, R., 1991. Simulation of the plastic response of whisker reinforced metal matrix composites under thermal cycling conditions. Scripta metallurgica et materialia 25, 2285-2290. 


\section{Table Caption}

Table 1 Material properties.

Table 2 Correlation between the fiber fraction volume and characteristic parameters of the array.

Table 3 Cyclic load points analyzed by a set of step-by-step analysis.

\section{Figure Caption}

Fig. 1. a) The unit cell used in the FEA; b) Applied cyclic loading.

Fig. 2. Effective elastic stress contours of $\mathrm{Al} / \mathrm{Al}_{2} \mathrm{O}_{3}$ and $\mathrm{Al} / \mathrm{SiC}$ composites with $\mathrm{V}_{\mathrm{f}}=19.63 \%$ subjected to (a) $\sigma_{\mathrm{p} 0}=80 \mathrm{MPa}, \Delta \theta_{0}=0^{\circ} \mathrm{C}$ and (b) $\sigma_{\mathrm{p} 0}=0, \Delta \theta_{0}=50^{\circ} \mathrm{C}$, respectively.

Fig. 3. Limit tension load $\sigma_{\mathrm{pl}}$ normalized to the matrix yield stress $\sigma_{\mathrm{y}}$ for $\mathrm{Al} / \mathrm{Al}_{2} \mathrm{O}_{3}$ and $\mathrm{Al} / \mathrm{SiC}$ composites.

Fig. 4. Shakedown and ratchet limit boundaries for the $\mathrm{Al} / \mathrm{Al}_{2} \mathrm{O}_{3}$ composite with $\mathrm{V}_{\mathrm{f}}=12.56 \%$.

Fig. 5. History of plastic strain magnitude for the cyclic load point A1, A2, A3, A4, A5 and A6, defined in Fig.4 and evaluated by a set of step-by-step analysis.

Fig. 6. Contours of effective ratcheting strain for the cyclic load points $\mathrm{A} 3$ and A6, and plastic strain range for the cyclic load points $\mathrm{A} 2$ and $\mathrm{A} 4$, for the $\mathrm{Al} / \mathrm{Al}_{2} \mathrm{O}_{3}$ composite with $\mathrm{V}_{\mathrm{f}}=12.56 \%$.

Fig. 7. Comparison of reverse plasticity limit $\Delta \theta_{\mathrm{rp}}$ between the composites $\mathrm{Al} / \mathrm{Al}_{2} \mathrm{O}_{3}$ and $\mathrm{Al} / \mathrm{S}_{\mathrm{i}} \mathrm{C}$.

Fig. 8. Comparison of ratchet limit $\Delta \theta_{\text {rtc }}$ between the composites $A 1 / \mathrm{Al}_{2} \mathrm{O}_{3}$ and $\mathrm{Al} / \mathrm{S}_{\mathrm{i}} \mathrm{C}$.

Fig. 9. Variation of the ratchet boundaries with the ratio r/a for the composite $A l / \mathrm{Al}_{2} \mathrm{O}_{3}$.

Fig. 10. Variation of the shakedown boundaries with the ratio r/a for the composite $\mathrm{Al} / \mathrm{Al}_{2} \mathrm{O}_{3}$.

Fig. 11. Variation of the relative ratchet boundaries with the ratio r/a for the composite $A 1 / \mathrm{Al}_{2} \mathrm{O}_{3}$.

Fig. 12. Comparison of relative ratchet limit between the composites $A l / \mathrm{Al}_{2} \mathrm{O}_{3}$ and $\mathrm{Al} / \mathrm{S}_{\mathrm{i}} \mathrm{C}$.

Fig. 13. Maximum plastic strain ranges and ratcheting strains per cycle of the $\mathrm{Al} / \mathrm{Al}_{2} \mathrm{O}_{3}$ and $\mathrm{Al} / \mathrm{S}_{\mathrm{i}} \mathrm{C}$ composites subjected to a wide range of varying cyclic thermal loads $\Delta \theta$ and constant $\sigma_{\mathrm{p}}=0 \mathrm{MPa}\left(\mathrm{V}_{\mathrm{f}}=\right.$ $12.56 \%)$.

Fig. 14. Maximum plastic strain ranges and ratcheting strains per cycle of the $\mathrm{Al} / \mathrm{Al}_{2} \mathrm{O}_{3}$ and $\mathrm{Al} / \mathrm{S}_{\mathrm{i}} \mathrm{C}$ composites subjected to a wide range of varying cyclic thermal loads $\Delta \theta$ and constant $\sigma_{\mathrm{p}}=20 \mathrm{MPa}\left(\mathrm{V}_{\mathrm{f}}=\right.$ $12.56 \%)$.

Fig. 15. Unified maximum plastic strain ranges $\Delta \bar{\varepsilon}_{\text {max }}^{p}$ for the low cycle fatigue assessment of both the $\mathrm{Al} / \mathrm{Al}_{2} \mathrm{O}_{3}$ and $\mathrm{Al} / \mathrm{S}_{\mathrm{i}} \mathrm{C}$ composites subjected to a wide range of varying cyclic thermal loads for $\mathrm{V}_{\mathrm{f}}=$ $12.56 \%$ 
Fig. 16. Unified maximum plastic strain ranges $\Delta \bar{\varepsilon}_{\max }^{p}$ for both $\mathrm{Al} / \mathrm{Al}_{2} \mathrm{O}_{3}$ and $\mathrm{Al} / \mathrm{SiC}$ composites subjected to a wide range of varying cyclic thermal loads for different values of $\mathrm{V}_{\mathrm{f}}$.

Fig. 17. Variation of the slope $m$ with the volume fraction $\mathrm{V}_{\mathrm{f}}$ for $\mathrm{Al} / \mathrm{Al}_{2} \mathrm{O}_{3}$ and $\mathrm{Al} / \mathrm{S}_{\mathrm{i}} \mathrm{C}$ composites concerning the straight lines shown in Fig. 16. 